\title{
Simple compared to covariate-constrained randomization methods in balancing baseline characteristics: a case study of randomly allocating 72 hemodialysis centers in a cluster trial
}

\author{
Ahmed A. Al-Jaishi ${ }^{1,2,3^{*}}$ (D), Stephanie N. Dixon ${ }^{1,3,4,5}$, Eric McArthur ${ }^{3}$, P. J. Devereaux ${ }^{2}$, Lehana Thabane ${ }^{2}$ and \\ Amit X. Garg ${ }^{1,2,3,4}$
}

\begin{abstract}
Background and aim: Some parallel-group cluster-randomized trials use covariate-constrained rather than simple randomization. This is done to increase the chance of balancing the groups on cluster- and patient-level baseline characteristics. This study assessed how well two covariate-constrained randomization methods balanced baseline characteristics compared with simple randomization.

Methods: We conducted a mock 3-year cluster-randomized trial, with no active intervention, that started April 1, 2014, and ended March 31, 2017. We included a total of 11,832 patients from 72 hemodialysis centers (clusters) in Ontario, Canada. We randomly allocated the 72 clusters into two groups in a 1:1 ratio on a single date using individual- and cluster-level data available until April 1, 2013. Initially, we generated 1000 allocation schemes using simple randomization. Then, as an alternative, we performed covariate-constrained randomization based on historical data from these centers. In one analysis, we restricted on a set of 11 individual-level prognostic variables; in the other, we restricted on principal components generated using 29 baseline historical variables.

We created 300,000 different allocations for the covariate-constrained randomizations, and we restricted our analysis to the 30,000 best allocations based on the smallest sum of the penalized standardized differences. We then randomly sampled 1000 schemes from the 30,000 best allocations. We summarized our results with each randomization approach as the median (25th and 75th percentile) number of balanced baseline characteristics. There were 156 baseline characteristics, and a variable was balanced when the between-group standardized difference was $\leq 10 \%$.
\end{abstract}

\footnotetext{
* Correspondence: Ahmed.AlJaishi@lhsc.on.ca

1 Lawson Health Research Institute, London, Ontario, Canada

2Department of Health Research Methods, Evidence, and Impact, McMaster University, Hamilton, ON, Canada

Full list of author information is available at the end of the article
}

(c) The Author(s). 2021 Open Access This article is licensed under a Creative Commons Attribution 4.0 International License, which permits use, sharing, adaptation, distribution and reproduction in any medium or format, as long as you give appropriate credit to the original author(s) and the source, provide a link to the Creative Commons licence, and indicate if changes were made. The images or other third party material in this article are included in the article's Creative Commons licence, unless indicated otherwise in a credit line to the material. If material is not included in the article's Creative Commons licence and your intended use is not permitted by statutory regulation or exceeds the permitted use, you will need to obtain permission directly from the copyright holder. To view a copy of this licence, visit http://creativecommons.org/licenses/by/4.0/ The Creative Commons Public Domain Dedication waiver (http://creativecommons.org/publicdomain/zero/1.0/) applies to the data made available in this article, unless otherwise stated in a credit line to the data. 
Results: The three randomization techniques had at least 125 of 156 balanced baseline characteristics in 90\% of sampled allocations. The median number of balanced baseline characteristics using simple randomization was 147 $(142,150)$. The corresponding value for covariate-constrained randomization using 11 prognostic characteristics was $149(146,151)$, while for principal components, the value was $150(147,151)$.

Conclusion: In this setting with 72 clusters, constraining the randomization using historical information achieved better balance on baseline characteristics compared with simple randomization; however, the magnitude of benefit was modest.

Keywords: Cluster randomized trial, Covariate-constrained, Randomization, Balanced allocation, Restricted randomization

\section{Introduction}

The cluster-randomized trial (CRT) study design is useful when the interventions are naturally implemented on groups of individuals $[1,2]$. In contrast to individually randomized trials, CRTs randomly allocate groups rather than independent individuals. Simple randomization is the most basic and straightforward type of random allocation. Each "randomized unit" is assigned purely by chance. However, suppose the total number of randomized units is small (e.g., fewer than 20 units). In that case, simple randomization may result in a moderate to a high probability of imbalance between the trial arms [3]. In two-group, parallel-arm, individual-level trials, some have suggested that including at least 1000 participants per group is required to provide sufficient protection against the imbalance of baseline characteristics [4]. In the CRT setting, it is often impossible to have such a large number of randomized units. In a systematic review of 300 CRTs, $50 \%$ of trials randomly allocated fewer than 21 clusters, and $75 \%$ allocated fewer than 52 clusters [5].

Observing between-group differences in a trial's baseline characteristics complicates the interpretation of observed treatment effects and threatens the trial's internal validity [6-8]. Other randomization techniques may help minimize the risk of imbalance on baseline measured characteristics when using parallel arm CRT designs [8]. These techniques are described as "restricted" or "constrained" and include stratification, matching, minimization, and covariate-constrained randomization. All restricted methods require a priori knowledge about participating clusters and the baseline measures used for the restriction process.

Covariate-constrained randomization can provide a better baseline balance than other allocation methods (e.g., simple random allocation, stratification, and minimization), especially when the number of randomized units is small (e.g., less than 20 clusters) [3, 8-10]. This manuscript focuses on covariate-constrained randomization, where we constrained the randomization process using two sets of baseline characteristics (either constraining on a set of prognostic variables or principal components). Principal components are a small set of artificial variables that explain most of the variance about a larger group of variables.

Covariate-constrained randomization limits the potential schemes available for selection among all possible allocations (called the randomization space). This method simultaneously balances several measured cluster- or individual-level characteristics to ensure that the two treatment arms are similar at baseline [8,9]. Briefly, the covariate-constrained randomization process includes (i) a priori identifying and specifying a limited number of key prognostic cluster- or individual-level variables associated with the outcome that will be used to constrain the randomization process (or a function of baseline characteristics, for example, principal components); (ii) when there are 20 or more clusters [7], either enumerating all or generating at least 100,000 allocation schemes; (iii) for each allocation scheme, estimating balance on the selected baseline characteristics according to some predefined balance metric (e.g., absolute differences, standardized differences, or another measure [11]); (iv) choosing a constrained randomization space containing a subset of allocations that are balanced on the constrained baseline characteristics (e.g., 10\% of the best allocations [11-13]); and (v) randomly selecting one allocation scheme from the constrained randomization space that will be used for the trial.

There is a trade-off between the potential for a better balance achieved on the constrained baseline characteristics and the potential concerns with highly restricted randomization $[9,12]$. These trade-offs can include (i) jeopardizing the appearance of impartiality, for example, if pairs of clusters always (or never) appear in the same arm [9, 12]; (ii) a departure from the nominal type I error when clusters with correlated outcomes have a very high or very low probability of being included in the same trial arm $[9,12]$; and (iii) a loss in statistical power when variables used in the constrained randomization do not associate with the trial outcome $[9,12]$. Also, covariate-constrained randomization uses 
historical data on recruited clusters to capture baseline information on demographics, patients' medical histories, and historical rates of the outcomes [14-16]. However, historical data may represent a "population for randomization" that is different from the "trial population"; the data may be several months to years old at the time of randomization. In an "open cohort" setting, information available at the randomization date cannot account for new participants entering the cohort during the trial period. Thus, the balance achieved at randomization with historical information does not guarantee a balance of the baseline characteristics during the trial period. It is important to note that the randomization design (i.e., constrained variables) needs to be considered at the analysis stage [17-19].

We conducted this study to understand the best practices for randomizing hemodialysis centers into two parallel groups in Ontario, Canada. The lessons learned from this study will help our group make informed decisions about randomization processes for several CRTs that we plan to advance.

\section{Motivating example}

The CRT is an attractive design in the hemodialysis setting, especially when implementing interventions at the dialysis center level $[15,20,21]$. In addition, the CRT design offers logistical and administrative advantages such as simplifying the trial organization when evaluating policy- or cluster-level intervention $[1,22]$.

Suppose that we wish to undertake a CRT with hemodialysis centers in Ontario, Canada. In this example, we used historical data from administrative data sources to conduct covariate-constrained randomization. The trial period was three years, from April 1, 2014, to March 31, 2017, with no active treatment. The primary outcome was a composite of time-to-first event for cardiovascular-related death or non-fatal major cardiovascular-related hospitalization (hospital admission for myocardial infarction, stroke, or congestive heart failure).

\section{Objectives}

This paper compared randomization methods for a twoarm, parallel-group CRT with the intent that all individuals within a given randomized center receive the same treatment. We randomized a moderate number of clusters (i.e., hemodialysis centers) using either simple randomization or covariate-constrained randomization with pre-trial historical records (the population for randomization). We performed the randomization on a single date and allowed patients to enter the cohort throughout the study period. We compared simple randomization to covariate-constrained randomization on balance achieved on a set of baseline characteristics during a 3-year trial period (the trial population). We constrained either on prognostic variables or principal components.

Our secondary aim was to assess whether, in the absence of any intervention, the allocation schemes selected through the constrained randomization process preserved (i) a null treatment effect on the primary outcome and (ii) a 5\% nominal type I error rate.

\section{Methods}

\section{Design and setting}

We used a CRT design of outpatient hemodialysis centers in Ontario, Canada, that cared for a minimum of 15 patients. In 2013, Ontario had approximately 13.5 million residents with universal healthcare and physician services [23]. In the same period, Ontario had 26 regional dialysis programs that oversaw over 100 hemodialysis centers caring for about 8000 in-center patients in the outpatient setting [24].

\section{Data sources}

We ascertained center- and patient-level characteristics using records from linked healthcare databases in Ontario, Canada (Additional file 1: Appendix 1) [25-38]. These datasets were linked using unique encoded identifiers and analyzed at ICES [39].

\section{Patients}

We included two populations of patients, the population for randomization and the trial population. The population for randomization included patients who were actively receiving in-center hemodialysis on April 1, 2013. The trial population included an open cohort of patients who received in-center hemodialysis on April 1, 2014, or began receiving in-center hemodialysis during the trial period.

\section{Baseline characteristics}

We identified two cluster- and 86 individual-level (total 88) baseline characteristics to describe each cohort (Additional file 1: Appendix 2); the cluster-level characteristics included the center size and historical rate for the primary outcome. There were 23 continuous, 58 binary, and 14 categorical baseline characteristics. Nine continuous baseline characteristics were also featured as categorical variables. We created a new binary (or "dummy") variable to indicate each level of a category's presence or absence. In total, we evaluated 156 continuous or binary candidate baseline characteristics.

\section{Randomization process Sequence generation}

We randomly allocated the 72 hemodialysis centers into two groups in a 1:1 ratio on a single date. Initially, we 
generated 1000 random allocation schemes using simple (unconstrained) randomization that required no information on baseline characteristics. This number of random allocations produced an estimate within $0.5 \%$ accuracy of the true hazard ratio of 1.00 with a $5 \%$ significance level and a standard deviation of 0.08 ; note, the true hazard ratio is 1.00 because there is no active intervention [40]. Then, as an alternative, we performed the covariate-constrained randomization using pre-trial historical records, which ended April 1, 2013 (see details below). Using PROC PLAN in SAS version 9.4 (SAS Institute Inc., NC, Cary), we generated 300,000 unique allocation schemes of the 72 centers (Additional file 1: Appendix 3). Greene (2017) suggested performing at least 100,000 allocations when there are at least 20 clusters; with our computational capacity, we enumerated 300,000 allocations.

\section{Covariate-constrained randomization}

We performed the covariate-constrained randomization in the following series of steps using baseline characteristics of the population for randomization $[6,8,9,41]$.

Step 1: Randomly selected 300,000 allocation schemes from the $4.43 \times 10^{20}$ possible allocation schemes.

Step 2: For each of the 300,000 allocation schemes, we restricted the randomization space using one of two constraining criteria [8].

i. We constrained the allocation on a set of 11 baseline characteristics deemed prognostic for the outcome, based on prior literature or clinical experience (Additional file 1: Appendix 4a).

ii. We constrained the allocation on principal components. A principal component analysis is a dimensionality reduction technique whereby a dataset with many variables is transformed into a smaller set of artificial variables (called principal components). These principal components ideally retain some or most of the meaningful properties of the original set of variables. We used the principal components to account for some of the variation in the observed data and as criterion variables in our constrained randomization process (Additional file 1: Appendix 4b).

We compared baseline differences between the two arms using standardized differences [42, 43], which describes the differences between group means or proportions relative to the pooled standard deviation.
Step 3: For each allocation scheme from the population for randomization, we counted the number of constrained variables with a standardized difference greater than $10 \%$ and calculated the sum of the constrained variables' standardized differences [42, 44]. We added a penalty of ten units to the sum of standardized differences for each imbalanced constrained variable. We imposed this penalty to favor allocation schemes that had the least number of imbalanced constrained baseline characteristics. For example, if the sum of standardized differences was two and three constrained variables were imbalanced, the penalized sum of standardized differences would be 32 .

From the 300,000 randomization schemes, we constrained the randomization space to the 30,000 best allocation schemes, based on the smallest sum of the penalized standardized differences [11-13]. From the 30,000 best allocations, we randomly sampled 1000 allocations to reduce the computational time for analysis $[11,12]$.

\section{Statistical analysis}

For the 1000 sampled schemes, we (i) estimated the percentage of times each center was allocated to each arm, (ii) estimated the percentage of times each combination of center pairs appeared in the same group [41], and (iii) calculated the standardized difference of all 156 baseline characteristics for the trial population. We then estimated the percentage of time each of the 156 baseline characteristics was balanced among the 1000 sampled randomization schemes, (iv) calculated the median (25th and 75th percentiles) number of baseline characteristics balanced for the trial population, and finally (v) estimated the unadjusted and adjusted hazard ratio between the randomized arms, for the time-to-first event of the composite outcome of cardiovascular-related death or a non-fatal cardiovascular-related hospitalization (see definition of outcome in Additional file 1: Appendix 5; this is a primary outcome for future trials that is highly relevant to patients and their providers). Using a generalized-estimating-equation extension for the Cox proportional hazard model, we estimated the hazard ratio with an exchangeable covariance matrix to account for within-center clustering $[22,45]$. For each of the 1000 sampled randomization schemes, the models were fitted to patient-level data from the trial population. We conducted unadjusted and another analysis adjusting for the randomization design (i.e., adjusted analyses using the constrained baseline characteristics by adding these variables into the model).

We stopped following patients on March 31, 2017, or earlier if they died. We summarized the hazard ratios as the mean with the 2.5th and 97.5th percentiles, 
corresponding to the hazard ratio estimate with a $95 \%$ confidence interval [46]. We expected to observe no between-group differences in the event rate of our primary outcome approximately $95 \%$ of the time (i.e., a nominal type I error of 5\%). The use of 1000 randomizations allowed us to detect a type I error between 3.6\% and $6.4 \%$ as not statistically different than $5 \%$; we used a standard test based on the normal approximation to the binomial distribution as described by Rosner (1995) [47].

\section{Results}

\section{Characteristics of cohorts}

The population for randomization $(n=5812)$ included all patients receiving in-center hemodialysis on April 1, 2013. The trial population $(n=11,832)$ included patients receiving hemodialysis on April 1, $2014(n=5410)$ and patients who started in-center hemodialysis during the 3 -year trial period $(n=6412)$. The trial population included 4415 patients (37\%) in the population for randomization. The median (25th and 75 th percentiles) number of patients in each center for the population for randomization was $61(28,105)$ and for the trial population was $131(55,227)$.

The population for randomization and the trial population differed on several baseline characteristics (Table 1 and Additional file 1). However, the differences were mainly attributed to the inherent differences between prevalent and new patients starting hemodialysis (e.g., length of time on dialysis, number of dialysis sessions in the prior year, healthcare service utilization, and general practitioner visits the preceding year.)

\section{Results from the principal component analysis}

We subjected 29 of the 156 baseline characteristics to principal component analysis (Additional file 1: Appendix 4b). We retained ten principal components that accounted for $61 \%$ of the 29 baseline characteristics variance. Additional files 1: Appendix 6 and 7 show results from the principal component analysis.

\section{Randomization of hemodialysis centers}

Each of the 72 participating centers had an approximately $50 \%$ chance of being randomized to either trial arm (see Additional file 1: Appendix 8 for the process and hardware specification). However, we observed that some pairs of centers were allocated to different trial arms at a different probability than we might have expected if we had used simple randomization (Fig. 1AC). In addition, these pairs of centers tended to be large and generally had over 225 patients.

\section{Balance of baseline characteristics}

Table 2 shows the balance for a select set of baseline characteristics by the method of constraining. In the trial population, both sets of constrained variables were generally well balanced between the two arms, regardless of the randomization method. However, the constrained randomizations generally provided a slightly better balance. Additional file 1: Appendix 9 shows the percentage of times each of the baseline characteristics (from the trial population) were balanced across the 1000 randomization schemes for the three allocation methods. Table 3 shows a summary of the number of baseline

Table.1 Select baseline characteristics. The population for randomization included patients on hemodialysis as of April 1, 2013. The trial population included an open cohort of patients receiving in-center hemodialysis on April 1, 2014, or began receiving in-center hemodialysis during the trial period between April 1, 2014, and March 31, 2017

\begin{tabular}{|c|c|c|c|}
\hline Baseline characteristic & Value & $\begin{array}{l}\text { Population for } \\
\text { randomization }\end{array}$ & $\begin{array}{l}\text { Trial } \\
\text { population }\end{array}$ \\
\hline Centers & Number of centers ( $n$, patients) & $72(n=5812)$ & $\begin{array}{l}72(n= \\
11,832)\end{array}$ \\
\hline \multirow[t]{4}{*}{ Center Size $^{a}$} & Mean \pm standard deviation & $81(69)$ & 164 (137) \\
\hline & 15 to 73 patients & $42(58 \%)$ & $\mathrm{N} / \mathrm{A}$ \\
\hline & 74 to 131 & $19(26 \%)$ & \\
\hline & 132 to 363 & $11(15 \%)$ & \\
\hline \multirow[t]{5}{*}{$\begin{array}{l}\text { The composite outcome of CV-related death or major CV- } \\
\text { related hospitalization }{ }^{b}\end{array}$} & $\begin{array}{l}\text { Historic rate per } 100 \text { person-years (cluster } \\
\text { standard deviation) }\end{array}$ & $10(3.7)$ & $11(3.3)$ \\
\hline & 0.00 to 6.60 & $11(15 \%)$ & $7(10 \%)$ \\
\hline & 6.70 to 9.90 & $14(19 \%)$ & $21(29 \%)$ \\
\hline & 10.0 to 13.2 & $26(36 \%)$ & $25(35 \%)$ \\
\hline & 13.3 to 23.1 & $21(29 \%)$ & $19(26 \%)$ \\
\hline
\end{tabular}

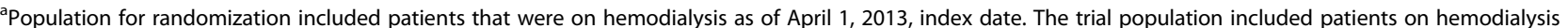
as of April 1, 2014, and any patient who started in-center hemodialysis at one of the 72 participating centers during the 3-year trial period. Follow-up ended on March 31, 2017. The index date was the first date patients entered the respective cohort. N/A = not applicable because the center's trial population had an open cohort, so the size was larger by design

${ }^{\mathrm{b}}$ The composite outcome of cardiovascular-related death or hospitalization for myocardial infarction, ischemic stroke, and congestive heart failure 


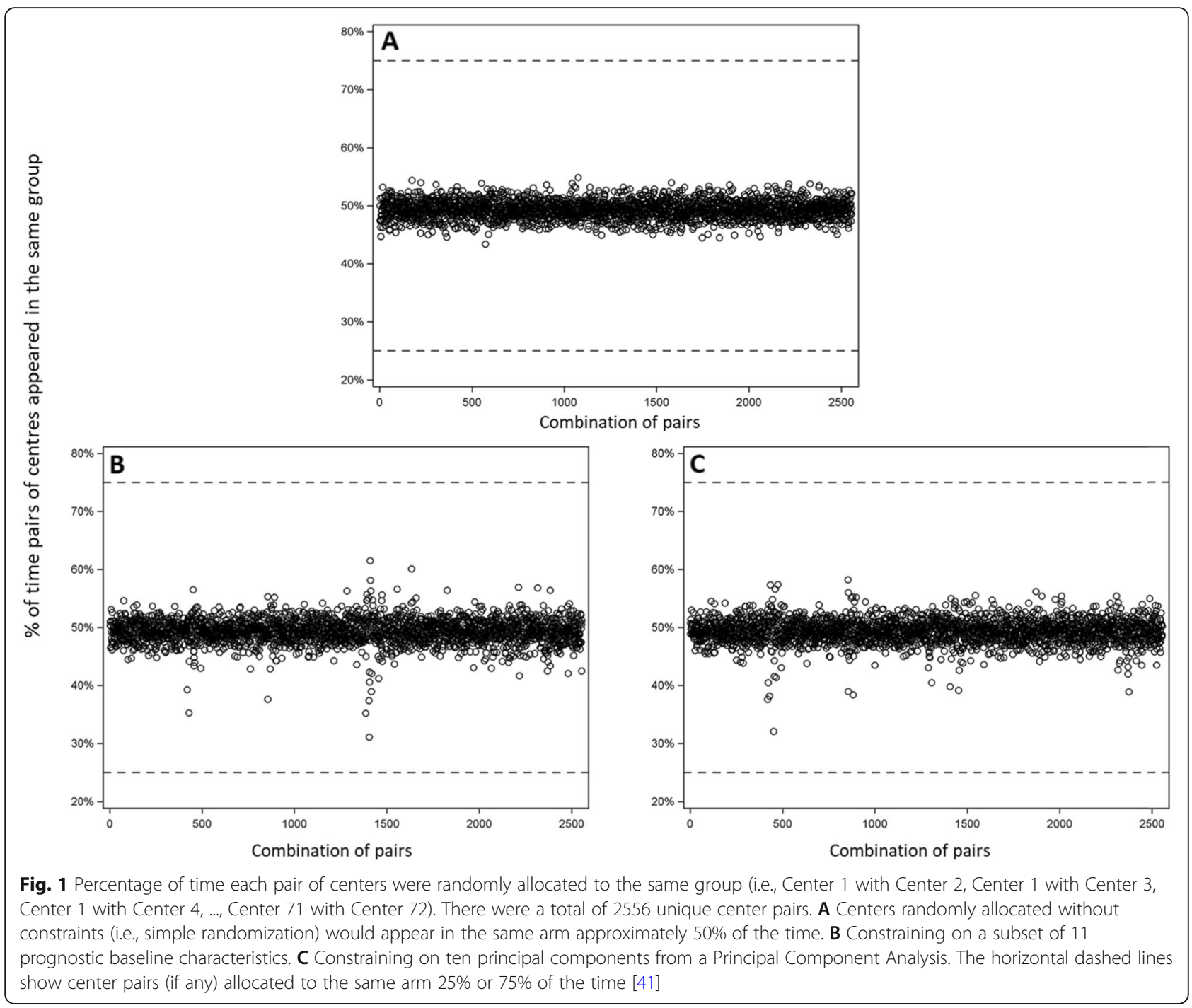

characteristics balanced across randomization schemes. The trial population had at least 125 of $156(80 \%)$ balanced baseline characteristics in $90 \%$ of simple randomization schemes. By comparison, the constrained methods always had slightly more balanced baseline characteristics (at least $85 \%$ of the 156 baseline characteristics were balanced in $90 \%$ of sampled allocations). Table 3 also shows the median (25th and 75th percentiles) number of balanced baseline characteristics across the 1000 sampled randomization schemes by allocation method.

\section{Cardiovascular-related death or major cardiovascular- related hospitalization}

We followed patients for an average of 1.7 years, and there were 2260 events over the 3-year follow-up. The event rate of the primary outcome was 11 per 100 person-years. Table 4 shows the results from the unadjusted and adjusted analyses for simple and covariate- constrained randomization methods. Across the 1000 simple randomization schemes for the trial population, the mean unadjusted hazard ratio (2.5th and 97.5th percentile) was $1.01(0.87,1.16)$, and $5.9 \%$ of allocation schemes produced a confidence interval for the hazard ratio that did not contain the null value of 1.00 . Compared to simple randomizations, constrained randomizations had similar unadjusted hazard ratios, with slightly narrower $95 \%$ confidence intervals. The type I error tended to be somewhat lower than the nominal level for some constrained methods than the unconstrained approach.

Adjusted analyses for the constrained methods produced narrower confidence intervals than the unadjusted analyses. However, the type I error was within the acceptable range only when models adjusted for the ten principal components; the type I error was outside the expected range for all other adjusted analyses. We also explored the results when adjusting for aggregate-level 
Table.2 The percentage of times each of the baseline characteristics was balanced across each of the 1000 randomizations schemes in the trial population

\begin{tabular}{|c|c|c|c|c|}
\hline \multirow[t]{2}{*}{ Baseline characteristic } & \multirow[t]{2}{*}{ Value } & \multicolumn{3}{|c|}{ Constrained randomization method } \\
\hline & & $\begin{array}{l}\text { Unrestricted/ } \\
\text { simple }\end{array}$ & $\begin{array}{l}\text { Prognostic baseline } \\
\text { characteristics }\end{array}$ & $\begin{array}{l}\text { Principal } \\
\text { components }\end{array}$ \\
\hline Center size & Mean \pm standard deviation & $32.9 \%$ & $41.8 \%$ & $38.7 \%$ \\
\hline $\begin{array}{l}\text { Composite outcome of CV-related death and major } \\
\text { CV-related hospitalization }\end{array}$ & Rate (per 100 person-year) & $32.5 \%$ & $36.2 \%$ & $33.5 \%$ \\
\hline \multirow[t]{5}{*}{ Age (years) } & Mean \pm standard deviation & $95.3 \%$ & $99.8 \%$ & $99.2 \%$ \\
\hline & $<65$ & $97.8 \%$ & $99.7 \%$ & $99.9 \%$ \\
\hline & 65 to 74 & $100.0 \%$ & $100.0 \%$ & $100.0 \%$ \\
\hline & 75 to 84 & $100.0 \%$ & $100.0 \%$ & $100.0 \%$ \\
\hline & 85 to 105 & $99.5 \%$ & $100.0 \%$ & $99.9 \%$ \\
\hline Sex & Male & $100.0 \%$ & $100.0 \%$ & $100.0 \%$ \\
\hline Living in a rural area & Yes & $63.0 \%$ & $84.2 \%$ & $65.8 \%$ \\
\hline \multirow[t]{6}{*}{ Etiology for end-stage kidney disease } & Diabetes & $93.0 \%$ & $94.5 \%$ & $95.0 \%$ \\
\hline & $\begin{array}{l}\text { Glomerulonephritis/autoimmune } \\
\text { diseases }\end{array}$ & $96.3 \%$ & $100.0 \%$ & $99.5 \%$ \\
\hline & Drug-induced nephropathy & $100.0 \%$ & $99.9 \%$ & $100.0 \%$ \\
\hline & Polycystic kidney disease & $100.0 \%$ & $100.0 \%$ & $100.0 \%$ \\
\hline & Renal vascular disease & $97.5 \%$ & $97.6 \%$ & $96.7 \%$ \\
\hline & Other & $88.3 \%$ & $91.9 \%$ & $91.6 \%$ \\
\hline \multirow[t]{5}{*}{ Race } & Asian & $75.0 \%$ & $81.3 \%$ & $88.1 \%$ \\
\hline & Black & $73.4 \%$ & $95.9 \%$ & $91.9 \%$ \\
\hline & White & $45.6 \%$ & $64.0 \%$ & $90.2 \%$ \\
\hline & Other & $56.6 \%$ & $65.7 \%$ & $77.5 \%$ \\
\hline & Unknown & $93.2 \%$ & $93.7 \%$ & $93.6 \%$ \\
\hline \multirow[t]{3}{*}{ First dialysis modality } & Home hemodialysis & $100.0 \%$ & $99.8 \%$ & $99.9 \%$ \\
\hline & In-center hemodialysis & $97.8 \%$ & $98.6 \%$ & $99.9 \%$ \\
\hline & Peritoneal dialysis & $97.4 \%$ & $98.7 \%$ & $99.8 \%$ \\
\hline \multirow[t]{5}{*}{ First vascular access used at dialysis start } & AV graft & $99.9 \%$ & $100.0 \%$ & $100.0 \%$ \\
\hline & Fistula & $98.9 \%$ & $99.1 \%$ & $99.4 \%$ \\
\hline & Catheter & $93.5 \%$ & $96.2 \%$ & $99.4 \%$ \\
\hline & PD catheter & $98.8 \%$ & $99.0 \%$ & $100.0 \%$ \\
\hline & Unknown & $92.4 \%$ & $93.8 \%$ & $94.3 \%$ \\
\hline \multirow[t]{3}{*}{ Most recent vascular access before the index date } & AV graft & $98.7 \%$ & $99.8 \%$ & $98.9 \%$ \\
\hline & Fistula & $91.9 \%$ & $94.8 \%$ & $97.7 \%$ \\
\hline & Catheter & $89.9 \%$ & $94.0 \%$ & $97.4 \%$ \\
\hline $\begin{array}{l}\text { Patients } 65+\text { years in ODB in the } 6 \text { months prior to } \\
\text { index date }\end{array}$ & Yes & $97.5 \%$ & $99.3 \%$ & $99.4 \%$ \\
\hline $\begin{array}{l}\text { Unique hypertensive drugs } 6 \text { months before the } \\
\text { index date }\end{array}$ & Mean \pm standard deviation & $97.1 \%$ & $99.9 \%$ & $99.5 \%$ \\
\hline \multirow[t]{5}{*}{ Prescribed hypertensive drugs } & $\begin{array}{l}\text { Angiotensin-converting enzyme } \\
\text { (ACE) inhibitors }\end{array}$ & $99.4 \%$ & $99.3 \%$ & $99.5 \%$ \\
\hline & Angiotensin I| receptor blocker & $90.7 \%$ & $96.1 \%$ & $96.9 \%$ \\
\hline & Beta-blockers & $99.7 \%$ & $100.0 \%$ & $99.9 \%$ \\
\hline & Calcium channel blocker & $98.1 \%$ & $100.0 \%$ & $99.6 \%$ \\
\hline & Diuretics & $91.9 \%$ & $97.0 \%$ & $95.6 \%$ \\
\hline
\end{tabular}


Table.2 The percentage of times each of the baseline characteristics was balanced across each of the 1000 randomizations schemes in the trial population (Continued)

\begin{tabular}{|c|c|c|c|c|}
\hline \multirow[t]{2}{*}{ Baseline characteristic } & \multirow[t]{2}{*}{ Value } & \multicolumn{3}{|c|}{ Constrained randomization method } \\
\hline & & $\begin{array}{l}\text { Unrestricted/ } \\
\text { simple }\end{array}$ & $\begin{array}{l}\text { Prognostic baseline } \\
\text { characteristics }\end{array}$ & $\begin{array}{l}\text { Principal } \\
\text { components }\end{array}$ \\
\hline $\mathrm{CABG} / \mathrm{PCl}$ & Yes & $99.4 \%$ & $99.5 \%$ & $100.0 \%$ \\
\hline Heart failure & Yes & $96.8 \%$ & $100.0 \%$ & $99.8 \%$ \\
\hline Diabetes mellitus & Yes & $99.0 \%$ & $100.0 \%$ & $100.0 \%$ \\
\hline Ischemic stroke & Yes & $100.0 \%$ & $100.0 \%$ & $100.0 \%$ \\
\hline Lower extremity amputation & Yes & $99.9 \%$ & $100.0 \%$ & $100.0 \%$ \\
\hline Lung disease (COPD) & Yes & $99.0 \%$ & $99.6 \%$ & $100.0 \%$ \\
\hline Myocardial infarction & Yes & $99.2 \%$ & $100.0 \%$ & $100.0 \%$ \\
\hline Major cancer & Yes & $100.0 \%$ & $100.0 \%$ & $100.0 \%$ \\
\hline Peripheral vascular disease & Yes & $90.7 \%$ & $97.2 \%$ & $91.4 \%$ \\
\hline \multirow[t]{5}{*}{ Modified Charlson comorbidity Score } & Mean \pm standard deviation & $96.8 \%$ & $99.9 \%$ & $100.0 \%$ \\
\hline & 2 & $97.7 \%$ & $100.0 \%$ & $100.0 \%$ \\
\hline & 3 & $100.0 \%$ & $100.0 \%$ & $100.0 \%$ \\
\hline & 4 & $100.0 \%$ & $100.0 \%$ & $100.0 \%$ \\
\hline & $5+$ & $98.9 \%$ & $100.0 \%$ & $100.0 \%$ \\
\hline Having a kidney transplant before the index date & Yes & $100.0 \%$ & $100.0 \%$ & $100.0 \%$ \\
\hline \multirow{6}{*}{$\begin{array}{l}\text { Number of hospital admissions in the year before the } \\
\text { index date }\end{array}$} & Mean \pm standard deviation & $93.9 \%$ & $98.4 \%$ & $98.4 \%$ \\
\hline & 0 & $78.4 \%$ & $76.4 \%$ & $81.1 \%$ \\
\hline & 1 to 3 & $99.5 \%$ & $99.6 \%$ & $99.9 \%$ \\
\hline & 4 to 6 & $99.4 \%$ & $99.6 \%$ & $99.5 \%$ \\
\hline & 7 to 9 & $100.0 \%$ & $99.9 \%$ & $100.0 \%$ \\
\hline & $10+$ & $92.1 \%$ & $92.0 \%$ & $94.6 \%$ \\
\hline $\begin{array}{l}\text { Long term care facility utilization in the year before } \\
\text { the index date }\end{array}$ & Yes & $81.3 \%$ & $86.6 \%$ & $86.1 \%$ \\
\hline Time since the first date on dialysis (days) & Mean \pm standard deviation & $88.1 \%$ & $94.0 \%$ & $94.4 \%$ \\
\hline
\end{tabular}

baseline characteristics as used in the randomization, which aligned with the results when we adjusted for individual-level variables (results not shown).

\section{Discussion}

This empirical study presented an example of using historical data to conduct covariate-constrained randomization that balances baseline characteristics for a parallel, two-group, cluster-randomized trial. We showed that constraining the random allocation using a historical cohort (i.e., a population for randomization) provides a better balance on baseline characteristics than simple randomization. However, we randomized a moderate number of clusters, and the magnitude of benefit was modest. Our results also suggested that modelbased adjustment for the constrained variables produced treatment effects with the nominal type I error that is narrower than those produced with simple randomization. However, researchers should constrain prognostic variables and adjust for the constrained variables at the analysis stage; otherwise, the type I error might deviate from the nominal level described in previous reports $[1,9,11,12,17,18]$.

In a review of 300 CRTs published between 2000 and 2008, Wright et al. found significant discrepancies between the restricted randomization used at the design stage and covariate adjustments at the analysis stage [48]. Wright et al. identified 174 CRTs that used designbased restricted randomization [48]. However, only 30 $(17.2 \%)$ of these studies reported an adjusted analysis for all the constrained variables.

From an analysis perspective, the analysis should account for the design that uses covariate-constrained randomization $[1,9,11,12]$. Otherwise, the type I error may deviate from the nominal level because clusters with highly correlated outcomes get separated into different treatment arms (as observed in Fig. 1B, C) [9]. Splitting correlated clusters into different treatment arms tends to (i) lower the type I error below the nominal level (in the unadjusted analyses), and (ii) decrease 
Table.3 Summary of the balanced baseline characteristics for the trial population

\begin{tabular}{|c|c|c|c|}
\hline \multirow[t]{2}{*}{ Criteria } & \multicolumn{3}{|c|}{ Constrained randomization method } \\
\hline & $\begin{array}{l}\text { Unconstrained/ } \\
\text { simple }\end{array}$ & $\begin{array}{l}\text { Prognostic baseline } \\
\text { characteristics }\end{array}$ & $\begin{array}{l}\text { Principal } \\
\text { components }\end{array}$ \\
\hline \multicolumn{4}{|l|}{11 prognostic characteristics ${ }^{c}$} \\
\hline $\begin{array}{l}\text { Number of constrained baseline characteristics that were balanced in all } 1000 \text { (100\%) } \\
\text { sampled allocations }\end{array}$ & 0 of $11(0 \%)^{a}$ & 2 of $11(18 \%)$ & 2 of $11(18 \%)$ \\
\hline $\begin{array}{l}\text { Number of constrained baseline characteristics that were balanced in at least } 950 \text { (95\%) } \\
\text { sampled allocations }\end{array}$ & 6 of $11(55 \%)$ & 10 of $11(91 \%)$ & 7 of $11(64 \%)$ \\
\hline $\begin{array}{l}\text { Number of constrained baseline characteristics that were balanced in at least } 900(90 \%) \\
\text { sampled allocations }\end{array}$ & 8 of $11(73 \%)$ & 10 of $11(91 \%)$ & 9 of $11(82 \%)$ \\
\hline $\begin{array}{l}\text { Median (25th and } 75 \text { th percentile) number of baseline characteristics that were balanced } \\
\text { across the } 1000 \text { selected randomization schemes }\end{array}$ & $10(9,11)^{b}$ & $11(10,11)$ & $10(10,11)$ \\
\hline \multicolumn{4}{|l|}{29 baseline characteristics used in the principal component analysis ${ }^{d}$} \\
\hline $\begin{array}{l}\text { Number of constrained baseline characteristics that were balanced in all } 1000 \text { (100\%) } \\
\text { sampled allocations }\end{array}$ & 8 of $29(28 \%)$ & 12 of $29(41 \%)$ & 12 of $29(41 \%)$ \\
\hline $\begin{array}{l}\text { Number of constrained baseline characteristics that were balanced in at least } 950 \text { (95\%) } \\
\text { sampled allocations }\end{array}$ & 19 of $29(66 \%)$ & 23 of $29(79 \%)$ & 25 of $29(86 \%)$ \\
\hline $\begin{array}{l}\text { Number of constrained baseline characteristics that were balanced in at least } 900(90 \%) \\
\text { sampled allocations }\end{array}$ & 24 of $29(83 \%)$ & 25 of $29(86 \%)$ & 26 of $29(90 \%)$ \\
\hline $\begin{array}{l}\text { Median (25th and 75th percentile) number of baseline characteristics that were balanced } \\
\text { across the } 1000 \text { selected randomization schemes }\end{array}$ & $27(26,28)$ & $28(27,28)$ & $28(28,29)$ \\
\hline \multicolumn{4}{|l|}{ All 156 available baseline characteristics } \\
\hline $\begin{array}{l}\text { Number of constrained baseline characteristics that were balanced in all } 1000 \text { (100\%) } \\
\text { sampled allocations }\end{array}$ & 41 of $156(26 \%)$ & 46 of $156(28 \%)$ & $\begin{array}{l}55 \text { of } 156 \\
(35 \%)\end{array}$ \\
\hline $\begin{array}{l}\text { Number of constrained baseline characteristics that were balanced in at least } 950 \text { (95\%) } \\
\text { sampled allocations }\end{array}$ & $\begin{array}{l}104 \text { of } 156 \\
(67 \%)\end{array}$ & 115 of $156(74 \%)$ & $\begin{array}{l}118 \text { of } 156 \\
(76 \%)\end{array}$ \\
\hline $\begin{array}{l}\text { Number of constrained baseline characteristics that were balanced in at least } 900 \text { (90\%) } \\
\text { sampled allocations }\end{array}$ & $\begin{array}{l}125 \text { of } 156 \\
(80 \%)\end{array}$ & 132 of $156(85 \%)$ & $\begin{array}{l}134 \text { of } 156 \\
(86 \%)\end{array}$ \\
\hline $\begin{array}{l}\text { Median ( } 25 \text { th and } 75 \text { th percentile) number of baseline characteristics that were balanced } \\
\text { across the } 1000 \text { selected randomization schemes }\end{array}$ & $147(142,150)$ & $149(146,151)$ & $150(147,151)$ \\
\hline
\end{tabular}

The trial population included patients on hemodialysis as of April 1, 2014, and new patients who started in-center hemodialysis during the 3-year follow-up. We conducted simple randomization without any restrictions

${ }^{\mathrm{a}}$ For example, for simple randomization, 2 of the 11 chosen prognostic baseline characteristics were always balanced across 1000 randomly sampled allocation schemes

${ }^{\mathrm{b}}$ For example, for simple randomization, 500 of 1000 allocation schemes had at least ten balanced baseline characteristics out of the 11 prognostic baseline characteristics. As such, there is a $50 \%$ probability that a randomly selected allocation will have at least 10 of the 11 prognostic baseline characteristics balanced and a $75 \%$ probability that at least 9 of the 11 prognostic baseline characteristics will be balanced

${ }^{c}$ Prognostic baseline characteristics: Constraining on a set of baseline characteristics that thought to be important a priori and included the following patient-level information: age at index date, living in a rural area, Black race, Modified Charlson comorbidity index, number of hospital visits in the previous 12 months, number of unique drugs the patient was prescribed in the 6 months before the index date, as well as history in the last 5 years of diagnosis for peripheral vascular disease, congestive heart failure, coronary artery disease, myocardial infarction, and number of nephrology consults in the previous 12 months before the index date

${ }^{d}$ Results are shown for the 29 baseline characteristics included in the principal component analysis. We did not include any cluster-level baseline characteristics in the constraining process

power slightly, although we might still expect substantial gains in power due to the assurance of balance on prognostic baseline characteristics $[9,49]$. Several analytical techniques can test for treatment effects and take into account the study design. These methods include mixed-effects models, bias-corrected generalized estimating equations, and randomization-based permutation tests.

In our motivating example, we used an analysis for the time-to-first event. In contrast, previous studies have focused their investigations primarily on continuous or binary outcomes $[1,9,11,12]$. Our results add to this literature showing a generalized estimating equationbased approach can yield results that maintain the nominal type I error after adjusting for the covariateconstrained design.

This study has some limitations. First, the trial population included a large percentage of patients (37\%) included in the population for randomization. Thus, our results may not apply to other designs, for example, CRTs where the population for randomization and the trial population are the same or settings where clusterand patient-level profiles change rapidly over time. Second, some historical data may lag by more than 1 year; 
Table.4 Mean hazard ratio (2.5th and 97.5th percentiles) for the composite outcome during a 3-year follow-up of patients on incenter hemodialysis

\begin{tabular}{|c|c|c|c|}
\hline Baseline characteristics adjusted in the analysis & $\begin{array}{l}\text { Mean HR } \\
\text { (2.5th and 97.5th } \\
\text { percentile) }\end{array}$ & $\begin{array}{l}\text { Width } \\
{\text { of } \mathrm{Cl}^{\text {a }}}\end{array}$ & $\begin{array}{l}\text { Type } \\
1 \\
\text { error }\end{array}$ \\
\hline \multicolumn{4}{|l|}{ Unadjusted analyses } \\
\hline Simple (i.e., unconstrained) randomization & $1.01(0.87,1.16)$ & 0.280 & $5.9 \%^{\mathrm{e}}$ \\
\hline Constrained on a minimal set of baseline characteristics ${ }^{\mathrm{b}}$ & $1.00(0.89,1.12)$ & 0.233 & $3.2 \%$ \\
\hline Constrained on a minimal set of baseline characteristics ${ }^{b}$ and historical rate of the primary outcome & $1.00(0.88,1.13)$ & 0.250 & $4.4 \%{ }^{\mathrm{e}}$ \\
\hline Constrained on a minimal set of baseline characteristics ${ }^{b}$ and cluster size at time of randomization & $1.00(0.88,1.14)$ & 0.260 & $5.2 \%^{\mathrm{e}}$ \\
\hline $\begin{array}{l}\text { Constrained on a minimal set of baseline characteristics }{ }^{b} \text {, historical rate of the primary outcome, and } \\
\text { cluster size at time of randomization }\end{array}$ & $1.00(0.88,1.13)$ & 0.247 & $4.5 \%{ }^{\mathrm{e}}$ \\
\hline Constrained on 10 principal components & $1.01(0.89,1.12)$ & 0.234 & $3.3 \%$ \\
\hline Constrained on 10 principal components and historic rate of primary outcome & $1.00(0.88,1.14)$ & 0.261 & $5.2 \%^{\mathrm{e}}$ \\
\hline Constrained on 10 principal components and cluster size at time of randomization & $1.00(0.87,1.14)$ & 0.264 & $4.1 \%{ }^{\mathrm{e}}$ \\
\hline $\begin{array}{l}\text { Constrained on ten principal components, the historical rate of the primary outcome, and cluster size at } \\
\text { time of randomization }\end{array}$ & $1.00(0.89,1.13)$ & 0.239 & $3.1 \%$ \\
\hline \multicolumn{4}{|l|}{ Adjusted for constrained baseline characteristics ${ }^{d}$} \\
\hline Constrained on a minimal set of baseline characteristics ${ }^{b}$ & $1.00(0.89,1.12)$ & 0.232 & $8.6 \%$ \\
\hline Constrained on a minimal set of baseline characteristics ${ }^{b}$ and historical rate of the primary outcome & $1.00(0.89,1.12)$ & 0.223 & $8.3 \%$ \\
\hline Constrained on a minimal set of baseline characteristics ${ }^{b}$ and cluster size at time of randomization & $1.00(0.89,1.11)$ & 0.221 & $9.8 \%$ \\
\hline $\begin{array}{l}\text { Constrained on a minimal set of baseline characteristics }{ }^{b} \text {, historical rate of the primary outcome, and } \\
\text { cluster size at time of randomization }\end{array}$ & $1.00(0.90,1.11)$ & 0.216 & $9.6 \%$ \\
\hline Constrained on 10 principal components & $1.00(0.90,1.11)$ & 0.203 & $5.2 \%^{\mathrm{e}}$ \\
\hline Constrained on 10 principal components and historic rate of primary outcome & $1.00(0.90,1.11)$ & 0.201 & $6.0 \%{ }^{\mathrm{e}}$ \\
\hline Constrained on 10 principal components and cluster size at time of randomization & $1.00(0.90,1.11)$ & 0.203 & $6.3 \%{ }^{\mathrm{e}}$ \\
\hline $\begin{array}{l}\text { Constrained on ten principal components, the historical rate of the primary outcome, and cluster size at } \\
\text { time of randomization }\end{array}$ & $1.00(0.91,1.11)$ & 0.201 & $6.4 \%^{\mathrm{e}}$ \\
\hline
\end{tabular}

All randomization methods had 1000 randomization schemes. The cohort included patients on dialysis as of April 1, 2014, and any patient who started in-center hemodialysis at one of the 72 participating centers during the 3-year follow-up

$H R$ hazard ratio, width of $C l$ width of confidence interval (i.e., upper minus lower confidence limit)

aThe confidence interval's width may not equal the difference between the lower and upper confidence limits because of rounding

bIncluded patient-level information: age, living in a rural area, Black race, Modified Charlson comorbidity index, number of hospital visits in the previous 12 months, number of unique drugs the patient was prescribed in the 6 months before the index date, as well as history in the last 5 years of diagnosis for peripheral vascular disease, congestive heart failure, coronary artery disease, myocardial infarction, and number of nephrology consults in the previous 12 months before the index date

"Type 1 error in the various constrained scenarios. Note: The nominal type 1 error is $5 \%$. The observed type 1 error was within an "acceptable range" if it fell

within the $95 \%$ confidence interval of the nominal value (i.e., between $3.6 \%$ and $6.4 \%$ )

${ }^{\mathrm{d}}$ Adjusted analyses included baseline characteristics used in the constraining process

${ }^{\mathrm{e}} \mathrm{An}$ acceptable type 1 error was observed for this method (i.e., between $3.6 \%$ and $6.4 \%$ )

thus, these results may not apply for populations at randomization less than or more than a year old. Third, our example cohort randomized a moderately large number of clusters; a previous review reported that $75 \%$ of published CRTs randomized fewer than 52 clusters. Covariate-constrained randomization may provide a better baseline balance compared to simple randomization when there are fewer clusters. Finally, our secondary objective does not constitute a formal test of the type I error. Computer simulations with more control over the generated data would be better suited. As such, the reader should interpret these results cautiously.

\section{Conclusions and guidance for future trials}

Although covariate-constrained randomization approaches used in this setting had modest improvement for balance, there may be substantial improvements in statistical power [12]. We propose the following recommendations (Table 5) for CRTs based on the empirical comparisons presented in this paper and other published literature. It is worth noting that these recommendations are based on a single setting, and while we anticipate similar findings in different contexts, a more formal statistical comparison would be beneficial. 
Table.5 Guidance for conducting covariate-constrained randomization

1. Identify prognostic baseline characteristics a priori using background literature, historical data, or previous trials.

2. Generate all (or at least 1000) simple randomizations to identify baseline characteristics that are always balanced between treatment arms (e.g., $\geq 95 \%$ of the time).

3. Carefully consider the number of variables added to the constraining process or consider using a dimensionality-reduction method for many variables (e.g., principal component analysis).

4. Consider the amount of missingness of constrained baseline characteristics prior to randomization.

5. Enumerate all possible allocation schemes when there are fewer than 20 clusters or at least 100,000 allocations otherwise.

1. Identify prognostic variables a priori using background literature, historical data, or previous trials. Previous work for individual-level randomized controlled trials showed increases in statistical power when analyses prespecified covariates strongly associated with the outcome. The adjusted covariates had a more considerable impact on statistical power when the prevalence was moderate to high (between 10\% and 50\%) [19, 50-52].

2. Researchers should consider generating all (or at least 1000) simple randomizations to identify baseline characteristics that are always or almost always balanced (e.g., >95\% of the time) between treatment arms. There would be no need to include these baseline characteristics in the constraining process; however, researchers can have these variables in the model-based adjustment to improve the estimates' precision. Importantly, all prognostic variables should be specified a priori [52].

3. Carefully consider the number of baseline characteristics used during the constraining process. Evidence from our study (and previous simulation studies) showed that over-constraining could result in clusters with highly correlated outcomes having a lower probability of being included in the same trial arm. Thus, over-constraining can lead to a type I error below the nominal level and slightly decrease power $[9,49]$.

4. Researchers can use a dimensionality-reduction method (e.g., principal component analysis) to reduce many dimensions of the prognostic variables to several criterion variables used in the constrained randomization process [53]. As above, all analyses should account for the dimensionality-reduction criterion at the analytic stage.

5. While the constraining process utilizes aggregate patient-level and cluster-level data, investigators should consider missingness when constraining the randomization on these variables. When appropriate, variables with missing data should be imputed before aggregating the variable at the cluster level [54].

6. Researchers should consider constraining the randomization space to the $10 \%$ best allocations. Furthermore, researchers should enumerate all possible randomization schemes when fewer than 20 clusters or at least 100,000 randomization schemes [12].

\section{Supplementary Information}

The online version contains supplementary material available at https://doi. org/10.1186/s13063-021-05590-1.

Additional file 1: Appendix 1. Common data sources used for population-based studies. Appendix 2. Complete list of 156 Baseline characteristics for the randomization and trial population cohorts. Appendix 3. Randomization of the 72 clusters using PROC PLAN in SAS. Appendix 4. a Prognostic baseline characteristics that were thought to be relevant a priori or correlated with the outcome from previous literature. $b$ Baseline characteristics from the Population for Randomization that were subjected to principal component analysis. Appendix 5. Algorithm for capturing primary composite outcome. Appendix 6. Results from Principal component analysis (PCA). Appendix 7. We used the principal axis method to extract the principal components. A varimax (orthogonal) rotation followed the principal axis method. Only the first ten components displayed eigenvalues greater than 1 (see Appendix 6), and the results of a scree test also suggested that only the first ten components were meaningful. Therefore, we retained the first ten components for rotation. Appendix 8. Hardware specification and optimization for running the constrained randomization process. Appendix 9. The percentage of times baseline characteristics were balanced across 1000 randomization schemes for the three techniques.

\section{Acknowledgements}

This study was supported by ICES, funded by an annual grant from the Ontario Ministry of Health and Long-Term Care (MOHLTC). Parts of this material are based on data and information compiled and provided by the $\mathrm{CH}$ Cancer Care Ontario (CCO), MOHLTC, and Ontario Service Reports. We thank IMS Brogan Inc. for the use of their Drug Information Database. The analyses, conclusions, opinions, and statements expressed herein are solely those of the authors and do not reflect those of the data sources; no endorsement is intended or inferred.

\section{Authors' contributions}

AAA and AXG conceived and led the study design. SND, EM, PJD, and LT contributed to the study design. AAA was responsible for data management and analysis. AAA drafted the manuscript. AAA is the guarantor. All authors contributed to manuscript revision and approved the final manuscript.

\section{Funding}

Ahmed Al-Jaishi was supported by the Allied Health Doctoral Fellowship from the Kidney Foundation of Canada, CIHR Doctoral Award, and McMaster University Michael DeGroote Scholarship. Stephanie Dixon's research is supported by a SPOR Innovative Clinical Trial Multi-Year Grant (MYG-151209) from CIHR. Amit Garg was supported by the Dr. Adam Linton Chair in Kidney Health Analytics and a Clinician Investigator Award from the CIHR. We received funding for this study from partnering organizations, including the Lawson Health Research Institute, Ontario Renal Network, Dialysis Clinic Inc., Heart and Stroke Foundation of Canada, and Canadian Institutes of Health Research (CIHR) Innovative Clinical Trials Initiative (Grant number: MYG-151209). Funding was also provided by the Ontario Strategy for Patient-Oriented Research SUPPORT Unit, supported by the Canadian Institutes of Health Research and the Province of Ontario. However, funding bodies had no role in the study's design, analysis, interpretation of data, or writing the manuscript. 


\section{Availability of data and materials}

While data sharing agreements prohibit ICES from making our study dataset publicly available, access may be granted to those who meet prespecified criteria for confidential access, available at www.ices.on.ca/das. In addition, the full dataset creation plan and underlying analytic code can be requested from the authors on the understanding that the computer programs may rely upon coding templates or macros that are unique to ICES and are therefore either inaccessible or may require modification.

\section{Declarations}

\section{Ethics approval and consent to participate}

We had the authorization to use data in this project under section 45 of Ontario's Personal Health Information Protection Act, which does not require a research ethics board review. The dataset from this study is held securely in the coded form at ICES. ICES is an independent, non-profit research institute whose legal status under Ontario's health information privacy law allows it to collect and analyze healthcare and demographic data, without consent, for health system evaluation and improvement.

\section{Consent for publication}

Not applicable.

\section{Competing interests}

The authors declare that they have no competing interests.

\section{Author details}

${ }^{1}$ Lawson Health Research Institute, London, Ontario, Canada. ${ }^{2}$ Department of Health Research Methods, Evidence, and Impact, McMaster University, Hamilton, ON, Canada. ${ }^{3}$ ICES, London, Ontario, Canada. ${ }^{4}$ Department Medicine, Epidemiology and Biostatistics, Western University, London, ON Canada. ${ }^{5}$ Department of Mathematics and Statistics, University of Guelph, Guelph, ON, Canada.

\section{Received: 25 February 2021 Accepted: 1 September 2021} Published online: 15 September 2021

\section{References}

1. Hayes RJ, Moulton LH. Cluster randomised trials. Boca Raton, FL: CRC Press; 2009. https://doi.org/10.1201/9781584888178.

2. Eldridge S, Kerry SM. A practical guide to cluster randomised trials in health services research. Chichester, West Sussex: Wiley; 2012. https://doi.org/10.1 002/9781119966241.

3. Perry M, Faes M, Reelick MF, Olde Rikkert MGM, Borm GF. Studywise minimization: a treatment allocation method that improves balance among treatment groups and makes allocation unpredictable. J Clin Epidemiol. 2010;63(10):1118-22. https://doi.org/10.1016/j.jclinepi.2009.11.014.

4. Chu R, Walter SD, Guyatt G, Devereaux PJ, Walsh M, Thorlund K, Thabane L Assessment and implication of prognostic imbalance in randomized controlled trials with a binary outcome - a simulation study. Gong Y, editor PLoS One. 2012;7:e36677 DOl: https://doi.org/10.1371/journal.pone.0036677.

5. Ivers NM, Taljaard M, Dixon S, Bennett C, McRae A, Taleban J, et al. Impact of CONSORT extension for cluster randomised trials on quality of reporting and study methodology: review of random sample of 300 trials, 2000-8. BMJ. 2011;343(sep26 1):-d5886. https://doi.org/10.1136/bmj.d5886.

6. Raab GM, Butcher I. Balance in cluster randomized trials. Stat Med. 2001;20: 351-65.

7. Carter BR, Hood K, Fisher R, Beller E, Gebski V, Keech A, et al. Balance algorithm for cluster randomized trials. BMC Med Res Methodol. 2008;8:65.

8. Ivers NM, Halperin IJ, Barnsley J, Grimshaw JM, Shah BR, Tu K, et al. Allocation techniques for balance at baseline in cluster randomized trials: a methodological review. Trials. 2012;13(1):120. https://doi.org/10.1186/17456215-13-120.

9. Moulton LH. Covariate-based constrained randomization of grouprandomized trials. Clin Trials. 2004;1(3):297-305. https://doi.org/10.1191/174 0774504cn024oa.

10. Xiao L, Lavori PW, Wilson SR, Ma J. Comparison of dynamic block randomization and minimization in randomized trials: a simulation study. Clin Trials. Clin Trials. 2011;8(1):59-69. https://doi.org/10.1177/17407745103 91683.
11. Li F, Lokhnygina Y, Murray DM, Heagerty PJ, DeLong ER. An evaluation of constrained randomization for the design and analysis of grouprandomized trials. Stat Med. 2016;35(10):1565-79. https://doi.org/10.1002/ sim.6813.

12. Li F, Turner EL, Heagerty PJ, Murray DM, Vollmer WM, DeLong ER. An evaluation of constrained randomization for the design and analysis of group-randomized trials with binary outcomes. Stat Med. 2017;36:3791-806.

13. Yu H, Li F, Gallis JA, Turner EL. cvcrand: A package for covariate-constrained randomization and the clustered permutation test for cluster randomized trials. R J. 2019;11(2):1-14. https://doi.org/10.32614/RJ-2019-027.

14. Dickinson LM, Beaty B, Fox C, Pace W, Dickinson WP, Emsermann C, et al. Pragmatic cluster randomized trials using covariate constrained randomization: a method for practice-based research networks (PBRNs). J Am Board Fam Med. 2015;28(5):663-72. https://doi.org/10.3122/jabfm.2015. 05.150001.

15. Al-Jaishi AA, Mclntyre CW, Sontrop JM, Dixon SN, Anderson S, Bagga A, et al. Major outcomes with personalized dialysate temperature (MyTEMP): rationale and design of a pragmatic, registry-based, cluster randomized controlled trial. Can J Kidney Heal Dis. 2020;7:1-18.

16. Dempsey AF, Pyrznawoski J, Lockhart S, Barnard J, Campagna EJ, Garrett K, et al. Effect of a health care professional communication training intervention on adolescent human papillomavirus vaccination a cluster randomized clinical trial. JAMA Pediatr. 2018;172(5):e180016. https://doi. org/10.1001/jamapediatrics.2018.0016.

17. Ford I, Norrie J, Ahmadi S. Model inconsistency, illustrated by the cox proportional hazards model. Stat Med. Stat Med. 1995;14(8):735-46. https:// doi.org/10.1002/sim.4780140804.

18. Ford I, Norrie J. The role of covariates in estimating treatment effects and risk in long-term clinical trials. Stat Med. Stat Med. 2002;21(19):2899-908. https://doi.org/10.1002/sim.1294

19. Kahan BC, Jairath $V$, Doré CJ, Morris TP. The risks and rewards of covariate adjustment in randomized trials: an assessment of 12 outcomes from 8 studies. Trials. 2014;15:139.

20. ClinicalTrials.gov [Internet]. Bethesda (MD): National Library of Medicine (US). 2000 Feb 29 - . Identifier NCT04079582, Outcomes of a Higher vs. Lower Hemodialysate Magnesium Concentration (Dial-Mag Canada); 2021. [cited 2020 Jan 20]. Available from: https://clinicaltrials.gov/ct2/show/NCT04 079582

21. HiLo | A pragmatic clinical trial [Internet]. [cited 2020 Jan 20]. Available from: https://hilostudy.org/

22. Donner A, Klar N. Design and analysis of cluster randomization trials in health research. Gooster L, Ueberberg A, editors. London: Arnold; 2000.

23. Statistics Canada. Population estimates, quarterly [Internet]. 2020 [cited 2020 Aug 12]. Available from: https://www150.statcan.gc.ca/t1/tbl1/en/tv.a ction?pid=1710000901

24. Webster G, Wu J, Williams B, Ivis F, de Sa E, Hall N. Canadian organ replacement register annual report: treatment of end-stage organ failure in Canada 2003 - 2012. Canadian Institute for Health Information: Ottawa; 2014

25. Moist LM, Trpeski L, Na Y, Lok CE. Increased hemodialysis catheter use in Canada and associated mortality risk: data from the Canadian organ replacement registry 2001-2004. Clin J Am Soc Nephrol. 2008;3(6):1726-32. https://doi.org/10.2215/CJN.01240308.

26. Ellwood AD, Jassal SV, Suri RS, Clark WF, Na Y, Moist LM. Early dialysis initiation and rates and timing of withdrawal from dialysis in Canada. Clin J Am Soc Nephrol. 2012;8:1-6.

27. Saczynski JS, Andrade SE, Harrold LR, Tjia J, Cutrona SL, Dodd KS, et al. A systematic review of validated methods for identifying heart failure using administrative data. Pharmacoepidemiol Drug Saf. 2012;21(Suppl 1):129-40. https://doi.org/10.1002/pds.2313.

28. Pladevall M, Goff DC, Nichaman MZ, Chan F, Ramsey D, Ortíz C, et al. An assessment of the validity of ICD Code 410 to identify hospital admissions for myocardial infarction: the Corpus Christi Heart Project. Int J Epidemiol. 1996;25(5):948-52. https://doi.org/10.1093/ije/25.5.948.

29. Tamariz $L$, Harkins T, Nair V. A systematic review of validated methods for identifying ventricular arrhythmias using administrative and claims data. Pharmacoepidemiol Drug Saf. 2012;21(Suppl 1):148-53. https://doi.org/10.1 002/pds.2340

30. Moist LM, Richards HA, Miskulin D, Lok CE, Yeates K, Garg AX, et al. A validation study of the Canadian Organ Replacement Register. Clin J Am Soc Nephrol. 2011;6(4):813-8. https://doi.org/10.2215/CJN.06680810. 
31. Oliver MJ, Quinn RR, Garg AX, Kim SJ, Wald R, Paterson JM. Likelihood of starting dialysis after incident fistula creation. Clin J Am Soc Nephrol. 2012 7(3):466-71. https://doi.org/10.2215/CJN.08920811.

32. Perl J, Wald R, McFarlane P, Bargman JM, Vonesh E, Na Y, et al. Hemodialysis vascular access modifies the association between dialysis modality and survival. J Am Soc Nephrol. 2011;22(6):1113-21. https://doi.org/10.1681/A SN.2010111155

33. Quinn RR, Laupacis A, Austin PPC, Hux JEJ, Garg AXA, Hemmelgarn BR, et al. Using administrative datasets to study outcomes in dialysis patients: a validation study. Med Care. 2010;48(8):745-50. https://doi.org/10.1097/MLR. Ob013e3181e419fd.

34. Al-Jaishi AA, Moist LM, Oliver MJ, Nash DM, Fleet JL, Garg AX, et al. Validity of administrative database code algorithms to identify vascular access placement, surgical revisions, and secondary patency. J Vasc Access. 2018; 112972981876200(6):561-8. https://doi.org/10.1177/1129729818762008.

35. Schultz SE, Rothwell DM, Chen Z, Tu K. Identifying cases of congestive heart failure from administrative data: a validation study using primary care patient records. Chronic Dis Inj Can. 2013;33(3):160-6. https://doi.org/10.24 095/hpcdp.33.3.06

36. Hennessy S, Leonard CE, Freeman CP, Deo R, Newcomb C, Kimmel SE, et al. Validation of diagnostic codes for outpatient-originating sudden cardiac death and ventricular arrhythmia in Medicaid and Medicare claims data. Pharmacoepidemiol Drug Saf. 2010;19(6):555-62. https://doi.org/10.1002/ pds.1869.

37. Hussain MA, Mamdani M, Saposnik G, Tu JV, Turkel-Parrella D, Spears J, et al. Validation of carotid artery revascularization coding in Ontario health administrative databases. Clin Investig Med Médecine Clin Exp. 2016;39(2): E73-8. https://doi.org/10.25011/cim.v39i2.26483.

38. Longenecker JC, Coresh J, Klag MJ, Levey AS, Martin AA, Fink NE, et al. Validation of comorbid conditions on the end-stage renal disease medical evidence report: the CHOICE study. Choices for Healthy Outcomes in Caring for ESRD. J Am Soc Nephrol. 2000;11(3):520-9. https://doi.org/10.1681/ASN. V113520.

39. ICES. Privacy at ICES [Internet]. [cited 2019 Nov 25]. Available from: https:// www.ices.on.ca/Data-and-Privacy/Privacy-at-ICES

40. Burton A, Altman DG, Royston P, Holder RL. The design of simulation studies in medical statistics. Stat Med. 2006;25(24):4279-92. https://doi.org/1 0.1002/sim.2673.

41. Greene EJ. A SAS macro for covariate-constrained randomization of general cluster-randomized and unstratified designs. J Stat Softw. 2017;77(Code Snippet 1). https://doi.org/10.18637/jss.v077.c01.

42. Austin PC. Using the standardized difference to compare the prevalence of a binary variable between two groups in observational research. Commun Stat Simul Comput. 2009;38(6):1228-34. https://doi.org/10.1080/0361091 0902859574.

43. Mamdani M, Sykora K, Li P, Normand ST, Streiner DL, Austin PC, et al. Reader ' $s$ guide to critical appraisal of cohort studies: 2. Assessing potential for confounding. BMJ. 2005;330(7497):960-2. https://doi.org/10.1136/bmj.330.74 97.960

44. Yang D, Dalton JE. A unified approach to measuring the effect size between two groups using SAS ${ }^{\oplus}$. Pap 335-2012 Present 2012 SAS Glob Forum. 2012; $1-6$.

45. Lin DY. Cox regression analysis of multivariate failure time data: the marginal approach. Stat Med. 1994;13(21):2233-47. https://doi.org/10.1002/ sim.4780132105

46. Wicklin R. Simulating data with SAS ๑. Cary, NC: SAS Institute Inc.; 2013

47. Rosner B. Fundamentals of biostatistics. Belmont, CA: Duxbury Press; 1995.

48. Wright N, Ivers N, Eldridge S, Taljaard M, Bremner S. A review of the use of covariates in cluster randomized trials uncovers marked discrepancies between guidance and practice. J Clin Epidemiol. Elsevier USA. 2015;68(6): 603-9. https://doi.org/10.1016/j.jclinepi.2014.12.006

49. Freedman LS, Green SB, Byar DP. Assessing the gain in efficiency due to matching in a community intervention study. Stat Med. Stat Med. 1990;9(8): 943-52. https://doi.org/10.1002/sim.4780090810.

50. Hernández AV, Steyerberg EW, Habbema JDF. Covariate adjustment in randomized controlled trials with dichotomous outcomes increases statistical power and reduces sample size requirements. J Clin Epidemiol. Pergamon. 2004;57:454-60

51. Hernández A V., Eijkemans MJC, Steyerberg EW. Randomized controlled trials with time-to-event outcomes: how much does prespecified covariate adjustment increase power? Ann Epidemiol. Ann Epidemiol; 2006;16:41-48.
52. Raab GM, Day S, Sales J. How to select covariates to include in the analysis of a clinical trial. Control Clin Trials. 2000;21(4):330-42. https://doi.org/10.101 6/S0197-2456(00)00061-1.

53. Silipo R, Widmann M. 3 New techniques for data-dimensionality reduction in machine learning [Internet]. 2019 [cited 2020 Aug 26]. Available from: https://thenewstack.io/3-new-techniques-for-data-dimensionality-reductionin-machine-learning/

54. Fiero MH, Huang S, Oren E, Bell ML. Statistical analysis and handling of missing data in cluster randomized trials: a systematic review. Trials. 2016;17:-72.

\section{Publisher's Note}

Springer Nature remains neutral with regard to jurisdictional claims in published maps and institutional affiliations.
Ready to submit your research? Choose BMC and benefit from:

- fast, convenient online submission

- thorough peer review by experienced researchers in your field

- rapid publication on acceptance

- support for research data, including large and complex data types

- gold Open Access which fosters wider collaboration and increased citations

- maximum visibility for your research: over $100 \mathrm{M}$ website views per year

At BMC, research is always in progress.

Learn more biomedcentral.com/submissions 